\title{
Erratum to: Nonlinear analysis of a microbial pesticide model with impulsive state feedback control
}

\author{
Tieying Wang • Lansun Chen
}

Published online: 2 June 2011

(C) Springer Science+Business Media B.V. 2011

\section{Erratum to: Nonlinear Dyn \\ DOI 10.1007/s11071-010-9828-x}

The Introduction to the original publication should have included a reference to a previous paper by the authors about the same basic model [1], explaining the difference with the new paper, where a strategy of impulsive state feedback control according to needs of some practical problems was used, rather than systems with continuous control and periodic impulsive control in the new paper.

\section{Reference}

1. Wang, T., Chen, L.: Dynamic complexity of microbial pesticide model. Nonlinear Dyn. 58, 539-552 (2009)
The online version of the original article can be found under doi:10.1007/s11071-010-9828-x.

T. Wang $(\varangle) \cdot$ L. Chen School of Mathematical Sciences, Dalian University of Technology, 116024 Dalian, P.R. China

e-mail: wangtieying2008@Yahoo.cn

T. Wang

College of Science, Dalian Nationalities University,

116605 Dalian, P.R. China 